Article

\title{
Work-Family Conflict on Sustainable Creative Performance: Job Crafting as a Mediator
}

\author{
Man Zhang ${ }^{1,2}$, Fan Wang ${ }^{1, *} \mathbb{*}$ and Anupam Kumar Das ${ }^{3}(\mathbb{C})$ \\ 1 School of Management, Shanghai University, Shanghai 200444, China; zhangmanah@126.com \\ 2 Information Center, Party School of Anhui Provincial Committee of C.P.C., Hefei 230022, Anhui, China \\ 3 Department of Management, University of Chittagong, Chattogram 4331, Bangladesh; dasanupam@cu.ac.bd \\ * Correspondence: avatarking@shu.edu.cn
}

Received: 13 August 2020; Accepted: 23 September 2020; Published: 28 September 2020

\begin{abstract}
The psychology of sustainability in terms of sustainable development for work-family conflict (WFC) in organizations has become increasingly relevant in sustainable human resource management research, and the pursuit of sustainable creative performance is an important aspect of corporate sustainable development. Taking a regulatory focus perspective, this study integrates a moderated-mediation model to examine the relationship between work-family conflict and sustainable creative performance. Data were collected from 203 supervisor-subordinate dyads from two branches of a high-end manufacturing enterprise in Shanghai, China. The results reveal that work-family conflict has a positive effect on sustainable creative performance through job crafting, and the effect is stronger when individuals show higher promotion regulatory focus. We discuss the theoretical and practical implications of the study, along with potential future research directions.
\end{abstract}

Keywords: sustainable creative performance; work-family conflict; job crafting; promotion regulatory focus

\section{Introduction}

Sustainability in people management goes beyond human resources management policies and practices, by including a broad and critical perspective of leading people responsibly and ethically [1]. A primary prevention perspective involves the psychology of sustainability and sustainable development [2,3]. Achieving quality of work-family balance and wellbeing are sustainability goals, as they allow positive organizational contexts which are key to mobilizing energy, coping with challenges, and innovation and sustainable development [4]. Correspondingly, a new area of research and intervention, namely the psychology of sustainability in terms of sustainable development for well-being in organizations (e.g., work-family conflict (WFC)) has become increasingly relevant in sustainable human resource management research [5-9].

Work-family conflict reflects the contradiction between work and family demands on individuals. Previous work reveals negative effects of work-family conflict for individuals and organizations, such as emotional exhaustion, decreased job satisfaction, etc. [10,11]. However, some scholars have advised that there may be a "bright side" to work-family conflict [12]. According to Mitchell (2019), work-family conflict reflects the difference between the individual's role ability and work requirements, implying that requiring more individual effort, which may lead to creative performance [12]. Moreover, sustainable creative performance is an important outcome for sustainable organizations, refers to the sustainable generation of novel and useful ideas that can be important for innovation and competitiveness in changing environments [13]. Although a few researchers have argued that this new perspective of work-family conflict may have an impact on innovation [14,15], to the best of our knowledge, there is not yet any related empirical study in the sustainable human resource management literature. Hence, 
it is necessary to answer the following question "what are the outcomes of work-family conflict and why?" More specifically, to clarify what psychological mechanism is stimulated when employees face work-family conflict, making it a considerable topic for research. Therefore, this study aims to bridge the gap and broaden the research on work-family conflict and creative performance based on a sustainable development perspective.

Drawing on regulatory focus theory [16-19], we developed an integrated model to examine the relationship between work-family conflict and sustainable creative performance. Work-family conflict implies a gap between an individual's abilities and the demands of the organization and their family that can prompt the individual to make changes $[20,21]$. Hence, it is reasonable to believe that work-family conflict is a catalyst for change in job content and boundaries, and we speculate that work-family conflict may be positively related to job crafting. A wide variety of literature has verified that the purpose of job crafting is to actively or passively reshape the working relationship or gain more creativity by matching one's preferences and abilities to organizational tasks [22-26]. Job crafting is an ongoing process to change the requirements and boundaries of tasks through shaping job demands to achieve a fit between tasks and personal capacity $[27,28]$. This process stimulates individual abilities and promotes the continuous improvement of creative performance.

Further, regulatory focus theory distinguishes promotion and prevention focus based on individual work purpose and vision [29]. Promotion regulatory focus emphasizes sensitivity to positive outcomes and a focus on reaching maximal goals [30], which is related to a proactive personality, while prevention focus emphasizes security-related concerns, such as maintaining safety and upholding duties and responsibilities. Given these concerns, individuals with a promotion-focus are looking around to advancement and gains, while prevention-focus individuals are maximally sensitive to no losses [30].

Facing work-family conflict, individuals with a promotion regulatory focus are more likely to identify job role requirements and actively make changes to increase the probability of achieving their goals [31]. Several studies investigating the relationship between job crafting and promotion regulatory focus have found that employees with high levels of promotion focus engage more readily in job crafting than individuals who score low on promotion focus [32-34]. We hypothesize that work-family conflict is positively related to sustainable creative performance via job crafting, with promotion regulatory focus playing a moderating role. To verify this speculation, we conduct a field survey and collect data from 80 sales teams and 203 supervisor-subordinate dyads from two branches of a high-end manufacturing enterprise in Shanghai, China.

The remainder of this paper is organized as follows. Section 2 introduces the theoretical background and hypotheses development. Sections 3 and 4 test this model with data from 203 dyads of 80 supervisors and their subordinates from two branches of a high-end manufacturing innovation-oriented company with long overtime hours in Shanghai, and then present the results. Section 5 discusses the findings, limitations, and future research directions, and Section 6 concludes the paper.

\section{Background and Hypotheses Development}

\subsection{Sustainable Creative Performance}

Individuals with high creative performance are generally considered a resource to leverage to optimize or improve the team and organizational productivity [35]. Following De Stobbeleir (2011), we consider that individuals who show a high level of sustainable creative performance may be more flexible in information comprehension, higher in internal motivation for innovation, and more conversant in new technology [35]. These personal traits may help individuals better apply their abilities to their work, promoting more useful ideas and creative products [36], further increasing organizational competitiveness. Hence, methods of improving creative performance have received a great deal of attention from companies. 
Relevant studies have shown that the factors affecting creative performance are related to both individuals and organizations. Individual trait differences like creative personality, emotional intelligence, and self-efficacy can affect intrinsic motivation related to innovation, and thus affect innovation [37]. Individuals with more positive personalities are more likely to innovate to gain better evaluations from leaders and colleagues [38]. Positive organizational factors, such as a strong organizational innovation climate, low time pressure, and harmonious team cooperation can also promote improvements in sustainable creative performance [38]. However, existing research mainly discusses the antecedents of sustainable creative performance in the field of the positive aspects of individuals and organizations, ignoring the influence of some negative factors.

\subsection{The Moderating Effect between Work-Family Conflict and Job Crafting via Promotion Regulatory Focus}

Work-family conflict is defined as a "form of inter-role conflict in which the role pressures from the work and family domains are mutually incompatible in some respects" [7]. Job demands and family desires are part of daily life for most adults [39], and work-family conflict is universal. Previous research has revealed that work-family conflict has negative effects, such as work dissatisfaction, emotional exhaustion, depression, and psychological strain and complaints [10,39-41]. Generally, environmental stimuli interact with an individual's subjective aspirations to form the individual's initiative behavior motivation, and work-family conflict indicates a subsequent decline in working conditions that may trigger pessimistic expectations of the outcome, leading to an adjustment in organizational citizenship behavior $[40,41]$. Consequently, it is reasonable to suspect that work-family conflict has a direct impact on job crafting.

In the light of regulatory focus theory, people with regulatory focus tendencies have more incentive to improve work-family conflict or avoid escalating it. Whether to achieve positive results or avoid negative results, individuals are bound to change the work mode or content embodied in the conflict, which can involve adjusting work scope, changing work objectives, or even changing the work relationships [42]. Regulatory focus theory also reveals that the pursuit of different work objectives causes individuals to redistribute existing resources, which may be reflected by adjusting work status and innovating working methods [32].

Promotion regulatory focus is related to advancement, such as growth, development, and cultivation [17]. Based on regulatory focus theory, an individual who offers a promotion focus represents the final state of their ideal as ambition and fulfillment, pays more attention to whether there are positive results in the goal pursuit process, and experiences more emotions related to elation and depression [16]. In recognizing or evaluating demands, individuals with a promotion focus are more susceptible to needs-related information, emotions related to joy or depression, and individual benefits [10]. Promotion regulatory focus will be fully aroused by an implicit increase in employee requirements, and it will encourage individuals to pay more attention to the causes of conflict, as individuals who exert a high level of promotion focus will consider more possibilities for regulating conflicts and are more open to solutions [8]. Work-family conflict can cause individual negative mood fluctuations associated with dissatisfaction and strain [9]. To avoid the spread of these emotions, individuals may adjust their psychological motivation to change their work patterns [10]. Conflict as a stimulus drives personal reflection, and individuals' subsequent decisions, which have an even greater possibility for changing the work status quo. Concurrently, work-family conflict can bring about a decline in leaders' evaluations of an individual's performance, and the expectation of a loss of personal benefits can also promote increased personal attention to conflict mitigation and goal achievement.

Accordingly, we contend that the influence triggered by work-family conflict to job crafting is moderated by promotion regulatory focus. The specific hypothesis is as follows:

Hypothesis 1 (H1): Promotion regulatory focus moderates the relationship between work-family conflict and job crafting, such that the positive relationship is stronger when promotion regulatory focus is high. 


\subsection{Job Crafting and Sustainable Creative Performance}

Tim et al. (2012) defined job crafting as "the changes employees make to balance their job demands and job resources with their personal abilities and needs." Previous studies have shown that job crafting is composed of three differentiation strategies: (1) Finding new challenges, (2) finding needful resources, and (3) reducing demands [43]. Essentially, work-family conflict is a management issue that challenges individuals' resource allocation capacity [43]. When individuals' jobs offer challenges and opportunities, they tap new potential or use their skills better, and may attempt to be more innovative to attain goals [44]. Seeking more resources is essential for positive employees' performance because an increase in resources can alleviate the imbalance or shortage of resources implied by work-family conflict [45]. The investment of resources is also necessary for sustainable creative performance based on its requirement of continuous investments of time, money, and energy [20]. Finally, reducing demands signifies decreasing the role demands of an individual's work, which will also narrow work role boundaries [19]. A reduction in job role requirements can relieve the pressure on individuals and release resources for follow-up innovative work.

Hence, we postulate the following relationship:

Hypothesis 2 (H2): Job crafting is positively related to sustainable creative performance.

\subsection{The Integrated Effect of Model}

To verify these hypotheses, we designed a two-stage moderated mediation model to describe the indirect positive relation from work-family conflict to sustainable creative performance via job crafting with promotion regulatory focus as a moderator. This model reveals the complicated influence mechanism between the multiple variables and explains the pervasive social phenomenon that embodies the relationship between implicit motivation and innovation. We integrate the above hypotheses to form a comprehensive model described by Hypothesis 3 :

Hypothesis 3 (H3): Work-family conflict positively and indirectly influences sustainable creative performance, while job crafting plays a mediating role. Concurrently, a high level of promotion regulatory focus promotes the relationship from work-family conflict to job crafting.

In sum, the conceptual model is shown in Figure 1.

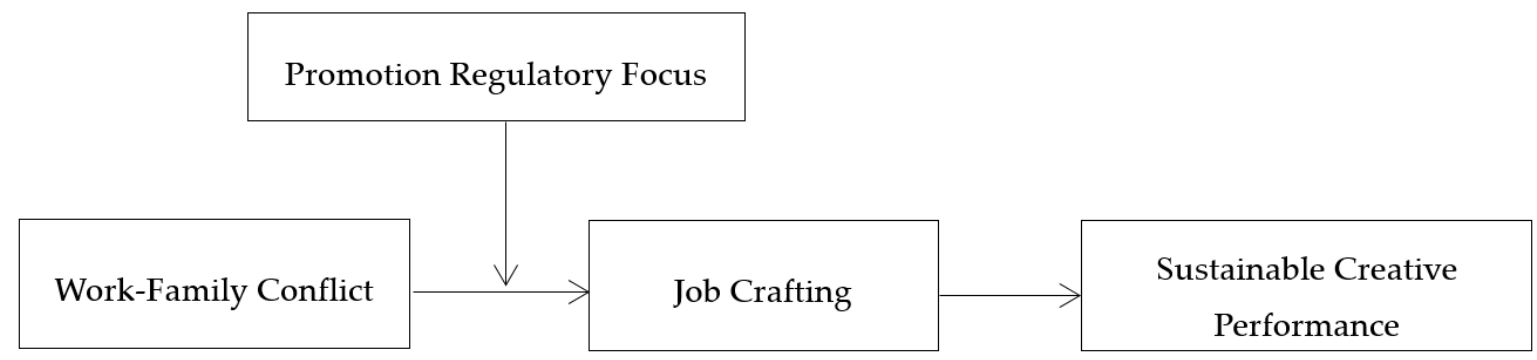

Figure 1. Conceptual model.

\section{Methods}

\subsection{Sample and Procedure}

After preliminary investigations of several companies, we selected two branches of a high-end manufacturing enterprise in Shanghai that interviews revealed have average overtime longer than in other companies as well as innovation is the main driving force of a company's performance, and where work-family conflict is prominent. We collected questionnaires from 203 dyads of 
80 supervisors and their subordinates. We selected full-time staff from R \& D, sales, customer relationship management, quality control, and other departments as the research objects. We invited participants to fill the questionnaire in some meeting rooms divided into 50 people each. We explained the purpose of the research, emphasizing that the research is only for scientific study purposes, besides, the questionnaire number and personnel code were issued in a one-to-one correspondence way to ensure the authenticity, confidentiality, and accuracy of the questionnaire survey. By analyzing the questionnaire data, we calculated that among the 203 employees, $60 \%(S D=0.493)$ of participants were women; the mean age was 35.891 years $(\mathrm{SD}=8.103)$; the average education level was 3.381 $(\mathrm{SD}=0.752,1=$ junior middle school, $2=$ high school, $3=$ junior college, $4=$ undergraduate, $5=$ master, $6=$ doctor), and their average annual income was 4.015 thousand yuan $(\mathrm{SD}=1.402)$. Moreover, 158 respondents care for at least one child, and nearly half of the respondents need to care for two elders. Although there are missing samples, the distribution of survey samples finally meets the requirements of random surveys as expected.

\subsection{Measures}

Our field survey combined subordinate self-reporting with supervisor evaluations to control common method variance. To reduce common method variance and illusionary correlations, we collected data from multiple sources. Employees' sustainable creative performance was rated by direct supervisors, whereas work-family conflict, job crafting, and promotion regulatory focus were self-reported. Because the survey was conducted within a Chinese company, we employed the back-translation process to use Chinese to express all relevant English [46]. All items used a 5-point Likert-type scale ( 1 = strongly disagree; $5=$ strongly agree; see Appendix A) as measurement options, and we used Cronbach's alpha to evaluate all scales' reliability.

\subsubsection{Work-Family Conflict}

Netemeyer (1996) 5-items scale was used to assess work-family conflict [47]. This scale is widely used in the research in related fields and has been proven to be applicable in the Chinese context [48]. A sample item is "The demands of my work interfere with my home and family life." The reliability coefficient for this scale is 0.911 .

\subsubsection{Job Crafting}

We used the seven-items from Leana (2009) to measure job crafting [49]. A sample item is "Introduce new approaches on your own to improve your work in the classroom." The scale's alpha reliability is 0.887 .

\subsubsection{Promotion Regulatory Focus}

Following Lockwood et al.'s advice, we used the four-items scale to measure the promotion regulatory focus [50]. A sample item is "I often think about how I will achieve my work goals." The Cronbach's alpha coefficient was 0.799.

\subsubsection{Sustainable Creative Performance}

Supervisors rated employee sustainable creative performance on a 5-items scale developed by George and Zhou et al. [51]. The scale included two dimensions: Innovation thought and innovation behavior. A sample item is "This person often uses creativity to develop new clients through different means and channels." 


\subsubsection{Control Variables}

Regarding control variables, we summarize previous studies to select potential variables. Existing studies have proven that individual imparities (such as gender and education level) accordingly impact sustainable creative performance [3], and scholars have also verified that income [21], gender [21], education level [22], and age [23] affect job crafting. We further control for job autonomy to avoid possible effects because previous studies have shown that job crafting is associated with job autonomy [52]. Besides, the number of children and parents living at home have an impact on individual work-family conflict [53]. Hence, we control these factors in the following analysis. This study used a 3-items job autonomy scale developed by Van et al., which was self-rated by employees [54]. An example item is "The job allows me any chance to use my personal initiative or judgment in carrying out the work." The Cronbach's alpha coefficient was 0.872 .

\subsection{Analysis Strategy}

Because sustainable creative performance is the supervisor's evaluation of their subordinates, and each supervisor may rate one or more subordinates, we nested individual data to form paired data. Considering the nested effects, we adopted a multilevel structural equation modeling (MSEM) approach to figure the independent variable's intraclass correlations (ICC (1)), which can specific that how many variances of creative performance were attributable to the supervisor-level factors. We used the LMS method proposed by Preacher, Zhang, and Zyphur (2016) [55] to test the moderating effect. To better examine the indirect effects of the mediated relationship, we used the parameter bootstrapping technique [56] to estimate the path coefficients by using Mplus 7.4 [57].

\section{Results}

\subsection{Preliminary Analyses}

The ICC (1) of supervisor-rated sustainable creative performance was 0.16 , which means that almost $16 \%$ of the variance in sustainable creative performance is attributable to group-level factors, so the data presented nested feature and the variance between groups had to be distinguished.

The means, standard deviations, and correlations of the variables are shown in Table 1, and the results provide preliminary evidence supporting our hypotheses. There was a significant negative correlation between gender and work-family conflict $(\mathrm{r}=-0.142, p<0.05)$, females may experience more work-family conflict, which was consistent with the conclusion of the previous research result [40]. Besides, we also found job crafting was significantly correlated with sustainable creative performance $(\mathrm{r}=0.195, p<0.01)$, and promotion regulatory focus was also significantly correlated with job crafting $(\mathrm{r}=0.425, p<0.01)$. The above correlation analysis provided preliminary support for further empirical analysis.

Table 1. Means, standard deviations, and correlations.

\begin{tabular}{|c|c|c|c|c|c|c|c|c|c|c|c|c|c|}
\hline Variables & $\mathbf{M}$ & SD & 1 & 2 & 3 & 4 & 5 & 6 & 7 & 8 & 9 & 10 & 11 \\
\hline 1. Education & 3.381 & 0.752 & & & & & & & & & & & \\
\hline 2. Income & 4.015 & 1.402 & $0.325 * *$ & & & & & & & & & & \\
\hline 3. Gender & 1.411 & 0.493 & -0.009 & $0.325^{* *}$ & & & & & & & & & \\
\hline 5. Children & 1.168 & 0.436 & -0.045 & -0.297 ** & 0.139 * & -0.089 & & & & & & & \\
\hline 6. Parent & 1.738 & 0.627 & $0.213 * *$ & 0.044 & 0.125 & -0.180 * & -0.001 & & & & & & \\
\hline 7. Job autonomy & 3.777 & 0.730 & $0.147^{*}$ & 0.075 & -0.016 & $-0.252 * *$ & -0.090 & -0.002 & $(0.872)$ & & & & \\
\hline 8. WFC & 2.691 & 1.121 & 0.079 & 0.116 & $-0.142 *$ & 0.094 & $0.152 *$ & 0.129 & -0.069 & $(0.911)$ & & & \\
\hline 11. SCP & 3.633 & 0.808 & -0.076 & 0.035 & $-0.166 *$ & 0.033 & -0.086 & -0.007 & $0.176 *$ & 0.136 & $0.195 * *$ & $0.147^{*}$ & $(0.902)$ \\
\hline
\end{tabular}

$n=203$. Internal consistency reliability appears in the diagonal brackets. Education was coded: $1=$ junior high school $2=$ technical or high school, $3=$ junior college, $4=$ bachelor, $5=$ master or above; ${ }^{*} p<0.05 ; * *<<0.01 ; * * *<<0.001$. Children: Number of children living at home; Parents: Number of parents living at home; SCP: Sustainable creativity performance; WFC: Work-family conflict; PRF: Promotion regulatory focus; SCP: Sustainable creativity performance. 


\subsection{Confirmatory Factor Analysis}

With the reason that the number of items measured oversteps the recommended sample size ratio, the scale items with three variables were packaged into three packages according to the previous study [58]. Fit indices of the root mean square error of approximation (RMSEA), comparative fit index (CFI), and Tucker-Lewis index (TLI) and and chi-square statistics were adopted to test the consistency of the research variables [59]. The results show that our integrated hypothesis model (model 4) fit better than other alternative models $(\chi 2=127.94 ; \mathrm{df}=59 ; \mathrm{CFI}=0.939 ; \mathrm{RMSEA}=0.063 ; \mathrm{TLI}=0.919)$. Therefore, the four variables in this study had good discriminate validity.

\subsection{Hypothesis Testing}

Table 2 shows the hierarchical regression analysis results from model 1. As model 4 shows, the interaction term coefficient $(\beta=0.087, p<0.01$ ) shows that promotion regulatory focus can moderator the relationship between work-family conflict and job crafting.

Table 2. Results of hierarchical regression analysis.

\begin{tabular}{|c|c|c|c|c|c|c|}
\hline \multirow{2}{*}{ Variables } & \multicolumn{4}{|c|}{ Job Crafting } & \multicolumn{2}{|c|}{$\begin{array}{l}\text { Sustainable Creative } \\
\text { Performance }\end{array}$} \\
\hline & Model 1 & Model 2 & Model 3 & Model 4 & Model 5 & Model 6 \\
\hline Intercept & $2.634^{* * *}$ & $2.641^{* * *}$ & $2.783^{* * *}$ & $2.807^{* * *}$ & $3.736^{* * *}$ & $2.640^{* *}$ \\
\hline Education & 0.066 & 0.066 & $0.072 *$ & $0.077 *$ & -0.121 & -0.148 \\
\hline Incoming & 0.013 & 0.013 & 0.012 & 0.011 & -0.008 & -0.014 \\
\hline Gender & -0.007 & -0.006 & 0.022 & 0.003 & $-0.273 *$ & -0.270 * \\
\hline Age & $0.008 *$ & $0.008 *$ & $0.007^{*}$ & $0.007 *$ & 0.000 & -0.004 \\
\hline Children & 0.066 & 0.063 & 0.049 & 0.019 & -0.104 & -0.131 \\
\hline Parent & 0.009 & 0.008 & -0.022 & -0.022 & 0.049 & 0.046 \\
\hline Job automony & $0.137^{* * *}$ & $0.138^{* * *}$ & $0.111^{* * *}$ & $0.120 * * *$ & $0.205^{*}$ & 0.148 \\
\hline Work-family conflict & & 0.004 & 0.005 & 0.001 & & \\
\hline Promotion regulatory focus & & & $0.213^{* * *}$ & $0.206^{* * *}$ & & \\
\hline Int & & & & $0.087^{* *}$ & & \\
\hline Job crafting & & & & & & $0.416^{* *}$ \\
\hline$\Delta \mathrm{F}$ & $3.820 * *$ & 0.043 & $39.177^{* * *}$ & $8.496^{* *}$ & $2.178 *$ & $5.576 * *$ \\
\hline $\mathrm{R}^{2}$ & 0.121 & 0.121 & 0.270 & 0.301 & 0.073 & 0.099 \\
\hline$\Delta \mathrm{R}^{2}$ & & 0.149 & $0.031^{* * *}$ & $0.031^{* *}$ & & $0.026^{* *}$ \\
\hline
\end{tabular}

Note: Un-standardized coefficients are reported with bootstrapping $95 \%$ confidence interval in parentheses. $n=82$ teams; bootstrapping sample size $=5000$. Int $=$ work-family conflict ${ }^{*}$ Promotion regulatory focus. ${ }^{*} p<0.05$; ${ }^{* *} p<0.01 ;{ }^{* * *} p<0.001$ (two-tailed).

Figure 2 further illustrates that a positive relationship is stronger when the promotion regulatory focus is high. Therefore, Hypothesis 1 is supported.

According to models 5 and 6 , job crafting is positively related to sustainable creative performance ( $\beta=0.416, p<0.01)$. Thus, Hypothesis 2 is supported.

We tested Hypothesis 3 by Bootstrapping the repeated parameter sampling method. The results showed that the overall conditional indirect effect $=0.05$, and the difference between the two groups was significant, the confidence interval range of $95 \%$ is [0.011, 0.251], excluding 0 . Thus, Hypothesis 3 is supported. 


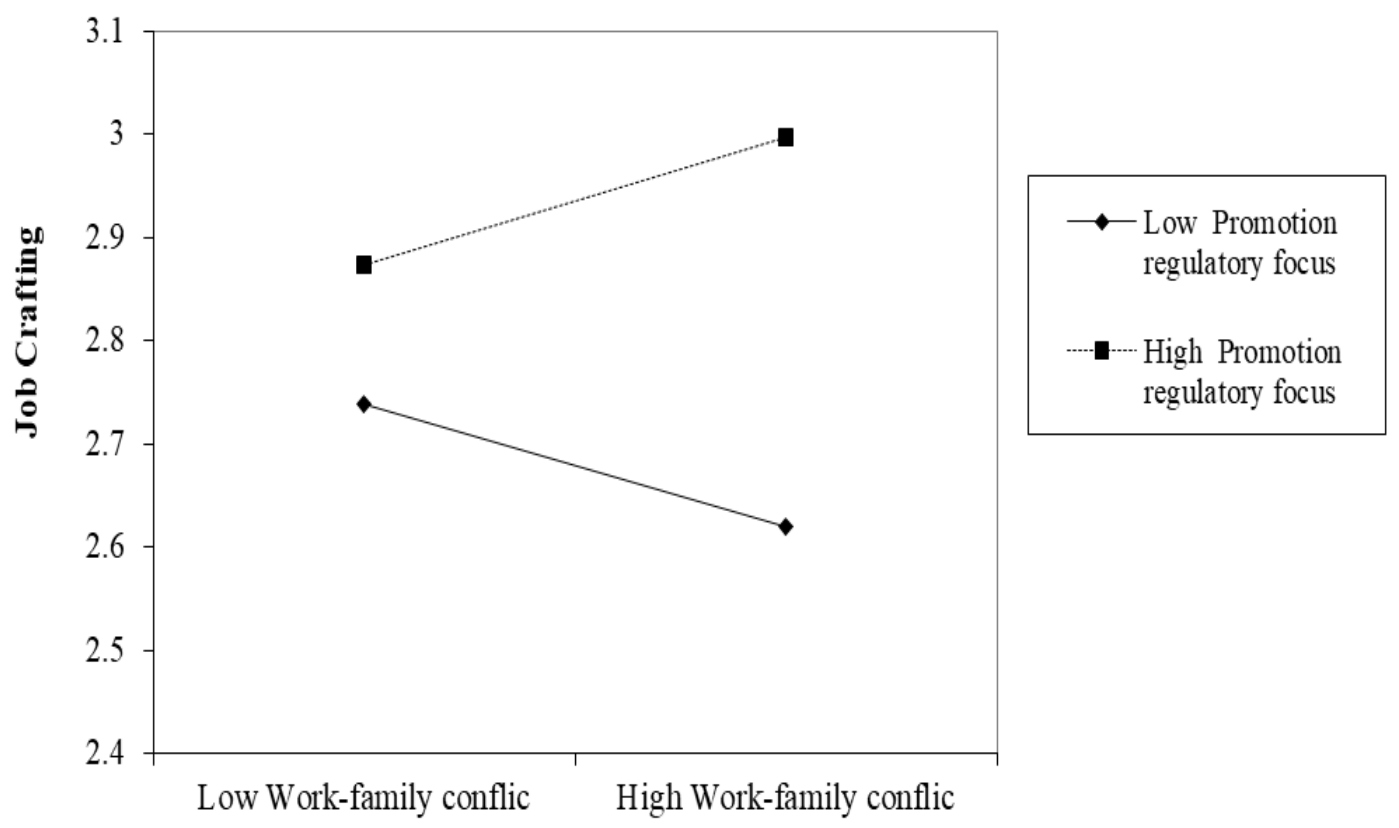

Figure 2. Promotion regulatory focus moderate relationships between work-family conflict and job crafting.

\section{Discussion}

Recently, sustainability as a hot topic has attracted increasing attention from scholars and enterprises [1-3], and rational use of resources has also become a hot topic because it is an important factor for the sustainable development of companies and individuals [60]. In general, resource imbalances and shortages negatively affect sustainable development, and work-family conflict reflects a resource imbalance between work and family roles, which implies a shortage of personal resources [61]. Negative emotions caused by work-family conflict can negatively affect work efforts, which will also cause negative job performance [62]. Although prior studies have not given this topic any attention, this study also found a bright side to the work-family conflict that can positively affect personal sustainable creative performance.

To better understand the consequences of work-family conflict, based on regulatory focus theory, our study indicates the relationship between work-family conflict and sustainable creative performance by deriving a four-variable comprehensive model. Further, we explored the mediating effect of job crafting and the moderating effect of promotion regulatory focus. The results highlight that promotion regulatory focus promotes the positive relation between work-family conflict and job crafting, which also facilitates the influence of job crafting on sustainable creative performance.

The results of the study suggest that work-family conflict can lead to positive changes in individuals. This result is inconsistent with previous studies on the negative consequences influencing work-family conflict, which include emotional exhaustion, work dissatisfaction, and increased turnover intention $[10,11]$. This inconsistency with previous conclusions provides a new direction for the differentiation of outcomes of work-family conflict, and also enriches and expands the work-family conflict research from a new perspective.

Furthermore, we explain the relationship between work-family conflict and sustainable creative performance by introducing job crafting as a mediation factor. Although there has been abundant research on job crafting and creative performance [24-27], less attention has been paid to the relationship between job crafting with work-family conflict. Our results suggest that self-regulation triggered by individual motivation can cause an individual's proactive change in the context of unbalanced resource allocation between work and family. With the function of promotion regulatory focus, the motivation to change becomes more obvious when individuals compare their current resource dilemma with their 
goal status, and the change will eventually promote job and personal competency matching, namely that individual innovation is related to resource allocation and individual motivation. In the past few years, scholars have realized and begun to study the dyadic typologies of work-family balance, namely work-family conflict and enrichment. Conclusions of this article are consistent with this latest trend. In other words, employees do not passively accept work-family conflicts, but take the initiative to seek balance or even enrichment [63].

\subsection{Theoretical Implications}

This study has several theoretical implications. First, our research reveals the positive consequences of work-family conflict by showing that it may be a double-edged sword with not only a negative side, but also a positive side. The origin of work-family conflict research was role theory [61], which represented the social consensus on the appropriate behavior of individuals in different positions. Different roles represent different demands, and role stress occurs when the needs of individuals in different roles are incompatible (such as employee and family member roles). Scholars believe that work-family conflict generally causes negative results such as marital dissatisfaction, turnover intention, and work-related strain [41,60,62]. However, our study revealed that there may be a positive tie between work-family conflict and work outcomes. Additionally, past studies on the consequences of work-family conflict have focused on personal emotions and work perceptions, and our study expands the research into personal performance and job redesign, which are more specifically about employee work behavior.

Second, we reveal the mechanism through which work-family conflict affects sustainable creative performance by using job crafting as a mediating factor. Past studies have suggested that work discretion and task complexity are associated with higher levels of job crafting behavior, and job crafting is associated with higher levels of work performance [64]. Our study extends the antecedents and consequences of job crafting by identifying the contradictory role demands implied in work-family conflict as a stimulus that accelerates job progression, and by substantiating sustainable creative performance to confirm the relationship between job crafting and creativity.

Third, we added promotion regulatory focus as a moderating factor to bind work-family conflict and job crafting. We demonstrated that promotion regulatory focus acts to enhance the positive relationship between work-family conflict and job crafting. We are the first to use promotion regulatory focus to reveal how differences in regulatory focus affect individual work behavior, and that its strength affects the relationship between conflict and individual creative performance [30-34]. It also helped us comprehend that an individual's goal pursuit can motivate them to be more proactive in solving problems in a negative environment. Different from previous studies, we study how individuals with this trait allocate resources to achieve their desired results by using promotion regulatory focus as an independent variable, and it suggests that personal behavior is not only influenced by environmental factors, but also by internal goals that affect work behavior and risk preference. Hence, our findings show that promotion regulatory focus plays an important role in individual organizational behavior.

Finally, our research enriches the regulatory focus theory. This paper explains individuals' reactions when facing work-family conflict by citing the regulatory focus perspective. These reactions are not only the embodiment of individual personality traits in a specific environment, but also the external manifestation of individual self-guidance. Moreover, we used this theory to better explain how controlling role demands in work-family conflict can promote individual innovation performance.

\subsection{Practical Implications}

Our research provides insights into sustainable human resource management and organizational practices. First, individuals need to continuously increase their resource input to achieve better performance evaluation; however, inevitably, individuals will not be able to balance the resource inputs of family and work due to limited personal experience [65]. When individuals encounter a conflict between the demands of work and family roles, they may try to change work boundaries or working 
styles to make work more compatible with their abilities. Similarly, we suggest that individuals who want to gain long-term competitive advantages should balance time and vigor allocation between work and family as imbalances weaken employee job and family satisfaction and hinder the growth of sustainable creative performance.

Second, supervisors should pay attention to the factors that affect their subordinates' sustainable creative performance; subordinates should be given more autonomy to make timely adjustments to their work to increase flexibility when the work environment irrelevantly hinders the development of personal potential [66]. Supervisors should influence subordinates' promotion regulatory focus through their desire for higher task objectives and establish positive publicity to subordinates with a high promotion regulatory focus to create a good team climate. By doing so, the team will regard the promotion regulatory focus as an important influence and be more willing to solve problems at work through job crafting. All of these are important for the team to achieve higher sustainable creative performance.

Third, organizations should consider more goal-oriented content when formulating rules and regulations rather than clarifying workflow by restricting individuals' daily work behaviors. Organizations should consider whether daily work content should be adjusted when individuals take the initiative to reconstruct their work due to a mismatch between work content and ability [67]. For employees who are perceived to be overqualified, organizations can increase the difficulty of work through post adjustments or task changes. Organizations should also provide more family role support services to employees when emphasizing that employees must fulfill their work role requirements, such as helping employees with childcare and offering insurance for employees' family members, as these reduce the burden on employees' families and release employees' energy for work tasks.

\subsection{Limitations and Future Study}

There are several limitations in the present study that should be noted and taken into consideration when interpreting the results, as well as provide direction for future research. First, the study was based on cross-sectional data that were collected from two high-tech companies. The data collected by this model can only judge the relationship, but not infer causality between the variables in the model. Hence, future studies should use longitudinal studies to determine causality, as the cross-sectional design did not compromise the relationships that exist in the model [68]. Besides, because our sample size was relatively moderate and we conducted our studies in only two companies, given the complex set of predictions, we cannot rule out the possibility that a sampling error may have affected the pattern of results observed in this study. Böckerman et al. (2012) suggested that they use nationally panel representative data to examine the role of employee job satisfaction in Finnish manufacturing plants over the period 1996-2001 to determine the extent to which it affects establishment level productivity [69]. In the light of this notion, we suggest that future researchers could explore such a method, thereby improving the WFC-creative performance study quality.

Second, the relationship between work-family conflict and sustainable creative performance involves only personal work and family. In particular, WFC is defined as the degree to which participation in the family role is made more difficult by virtue of participation in the work role. It is bi-directional which work can interfere with family, but family can also interfere with work as family-work conflict (FWC). One frequently mentioned, and as yet important difference between WFC and FWC is that WFC is more likely to be the impact of work-related variables, while FWC is more likely to be affected by family-related variables. Since creative performance is a work-related variable, we pay more attention to WFC. However, we encourage future researchers to take the factors of WFC and FWC into account.

Third, we reveal the degree to which it affects work-family conflict and job crafting by incorporating promotion regulatory focus as a moderator. Although promotion regulatory focus is a special type of regulatory focus, we encourage more research into the effects of prevention regulatory focus on this relationship, as prevention regulatory focus reflects an individual's greater awareness of 
risk and management of future expectations. Besides, the data were collected from employees working in two companies from China. Specific organization or Chinese cultural characteristics (e.g., high collectivist tendency) may limit the generalizability of the results. Future research could address this limitation by comparing finding based on different cultures and organizations.

Finally, in line with other published studies, we may not have done enough to minimize the proportion of nonresponses. A recent study proposed advanced solutions for missing data to maximize the use of data in analysis [70]. We suggest that future studies could apply for processing missing data by S Grund (2018) [70] to achieve a better quality of research design and a robust conclusion.

\section{Conclusions}

To sum up, work-family conflict as a basic role conflict has received increasing attention from scholars [71], we discuss the positive influence of this conflict from different perspectives by revealing the influence mechanism of work-family conflict and work crafting. Our study promotes a more comprehensive understanding of the consequences of work-family conflict. As a type of performance evaluation system, sustainable creative performance reflects the sustainable competitive advantages of organizations and individuals, and is a result that organizations and individuals focus on. It is important to research the antecedents of sustainable creative performance to improve task performance. Our conclusions are significant because we extend the research through introducing work-family conflict with improved sustainable creative performance with positive outcomes, which is generally thought to have only negative outcomes [72,73]. We hope that our study will inspire scholars to continue to study the antecedents of sustainable creative performance and the positive effects of work-family conflict.

Author Contributions: Conceptualization, M.Z., F.W., and A.K.D.; methodology, F.W. and M.Z.; software, M.Z. and F.W.; validation, M.Z. and A.K.D.; formal analysis, M.Z.; writing-original draft preparation, M.Z.; writing-review and editing, A.K.D., M.Z., and F.W.; visualization, M.Z. and F.W.; supervision, F.W.; project administration, M.Z.; funding acquisition, F.W. and M.Z. All authors have read and agreed to the published version of the manuscript.

Funding: This research received no external funding

Conflicts of Interest: The authors declare no conflict of interest.

\section{Appendix A}

\section{Work-Family Conflict}

1. The demands of my work interfere with my home and family life.

2. The amount of time my job takes up makes it difficult to fulfill family responsibilities.

3. Things I want to do at home do not get done because of the demands my job puts on me.

4. My job produces strain that makes it difficult to fulfill family duties.

5. Due to work-related duties, I have to make changes to my plans for family activities.

\section{Job Crafting}

1. Introduce new approaches on your own to improve your work in the classroom.

2. Change minor work procedures that you think are not productive (such as lunch time or transition routines) on your own.

3. On your own, change the way you do your job to make it easier for yourself.

4. Rearrange equipment or furniture in the play areas of your classroom on your own.

5. Organize special events in your classroom (such as celebrating a child's birthday, etc.) on your own.

6. On your own, bring in other materials from home for the classroom (such as empty jars or egg cartons).

\section{Promotion Regulatory Focus}


1. I am focused on achieving positive outcomes in my life.

2. I typically focus on the successes I hope to achieve in the future.

3. I often think about how I will achieve my work goals.

4. I am more orientated towards achieving success than preventing failure.

\section{Sustainable Creativity Performance}

1. Comes up with creative solutions to problems.

2. Comes up with new and practical ideas to improve performance.

3. Searches out new technologies, processes, techniques, and/or product ideas.

4. Not afraid to take risks.

5. Analyzing problems from new perspectives.

\section{References}

1. Di Fabio, A. The Psychology of Sustainability and Sustainable Development for Well-Being in Organizations. Front. Psychol. 2017, 8, 1534. [CrossRef] [PubMed]

2. Hameed, T.; Von Staden, P.; Kwon, K.-S. Sustainable Economic Growth and the Adaptability of a National System of Innovation: A Socio-Cognitive Explanation for South Korea's Mired Technology Transfer and Commercialization Process. Sustainability 2018, 10, 1397. [CrossRef]

3. De Prins, P.; Stuer, D.; Gielens, T. Revitalizing social dialogue in the workplace: The impact of a cooperative industrial relations climate and sustainable HR practices on reducing employee harm. Int. J. Hum. Resour. Manag. 2018, 31, 1684-1704. [CrossRef]

4. Manuti, A.; Giancaspro, M.L. People Make the Difference: An Explorative Study on the Relationship between Organizational Practices, Employees' Resources, and Organizational Behavior Enhancing the Psychology of Sustainability and Sustainable Development. Sustainability 2019, 11, 1499. [CrossRef]

5. Santos, G.G.; Cabral-Cardoso, C. Work-family culture in academia: A gendered view of work-family conflict and coping strategies. Gend. Manag. Int. J. 2008, 23, 442-457. [CrossRef]

6. Santos, G.G. Narratives about Work and Family Life among Portuguese Academics. Gend. Work Organ. 2014, 22, 1-15. [CrossRef]

7. Wayne, J.H.; Butts, M.M.; Casper, W.J.; Allen, T.D. In Search of Balance: A Conceptual and Empirical Integration of Multiple Meanings of Work-Family Balance. Pers. Psychol. 2016, 70, 167-210. [CrossRef]

8. Williams J, C. Will working mothers take your company to court? Harv. Bus. Rev. 2012, 90, 94-100. [CrossRef]

9. Kramar, R. Beyond strategic human resource management: Is sustainable human resource management the next approach? Int. J. Hum. Resour. Manag. 2013, 25, 1069-1089. [CrossRef]

10. Liu, W.; Zhang, P.; Liao, J.; Hao, P.; Mao, J. Abusive supervision and employee creativity. Manag. Decis. 2016, 54, 130-147. [CrossRef]

11. McCoy, S.K.; Hutchinson, S.; Hawthorne, L.; Cosley, B.J.; Ell, S.W. Is pressure stressful? The impact of pressure on the stress response and category learning. Cogn. Affect. Behav. Neurosci. 2014, 14, 769-781. [CrossRef] [PubMed]

12. Siqueira, R.P.; Pitassi, C. Sustainability-oriented innovations: Can mindfulness make a difference? J. Clean. Prod. 2016, 139, 1181-1190. [CrossRef]

13. Villajos, E.; Tordera, N.; Peiró, J.M. Human Resource Practices, Eudaimonic Well-Being, and Creative Performance: The Mediating Role of Idiosyncratic Deals for Sustainable Human Resource Management. Sustainability 2019, 11, 6933. [CrossRef]

14. Lin, L.-H. Electronic human resource management and organizational innovation: The roles of information technology and virtual organizational structure. Int. J. Hum. Resour. Manag. 2011, 22, 235-257. [CrossRef]

15. Brockner, J.; Higgins, E. Regulatory Focus Theory: Implications for the Study of Emotions at Work. Organ. Behav. Hum. Decis. Process. 2001, 86, 35-66. [CrossRef]

16. Senbeto, D.L.; Hon, A.H.Y. A Dualistic Model of Tourism Seasonality: Approach-Avoidance and Regulatory Focus Theories. J. Hosp. Tour. Res. 2019, 43, 734-753. [CrossRef]

17. Higgins, E.T.; Scholer, A.A. Engaging the consumer: The science and art of the value creation process. J. Consum. Psychol. 2009, 19, 100-114. [CrossRef] 
18. Gutnick, D.; Walter, F.; Nijstad, B.A.; De Dreu, C.K. Creative performance under pressure: An integrative conceptual framework. Organ. Psychol. Rev. 2012, 2, 189-207.

19. De Cooman, R.; Stynen, D.; Broeck, A.V.D.; Sels, L.; De Witte, H. How job characteristics relate to need satisfaction and autonomous motivation: Implications for work effort. J. Appl. Soc. Psychol. 2013, 43, 1342-1352. [CrossRef]

20. Kelly, E.; Moen, P.; Tranby, E. Changing Workplaces to Reduce Work-Family Conflict. Am. Sociol. Rev. 2011, 76, 265-290. [CrossRef]

21. Tims, M.; Bakker, A.B. Job crafting: Towards a new model of individual job redesign. SA J. Ind. Psychol. 2010, 36, 1-9. [CrossRef]

22. Mäkikangas, A.; Bakker, A.B.; Schaufeli, W.B. Antecedents of daily team job crafting. Eur. J. Work Organ. Psychol. 2017, 26, 421-433. [CrossRef]

23. Wrzesniewski, A.; Dutton, J.E. Crafting a Job: Revisioning Employees as Active Crafters of Their Work. Acad. Manag. Rev. 2001, 26, 179. [CrossRef]

24. Berg, J.M.; Dutton, J.E.; Wrzesniewski, A. Job crafting and meaningful work. Purp. Mean. Workplace 2013, 81, 81-104. [CrossRef]

25. Petrou, P.; Demerouti, E.; Schaufeli, W. Job crafting in changing organizations: Antecedents and implications for exhaustion and performance. J. Occup. Health Psychol. 2015, 20, 470-480. [CrossRef]

26. Tims, M.; Bakker, A.B.; Derks, D.; van Rhenen, W. Job Crafting at the Team and Individual Level. Group Organ. Manag. 2013, 38, 427-454. [CrossRef]

27. Zhang, F.; Parker, S.K. Reorienting job crafting research: A hierarchical structure of job crafting concepts and integrative review. J. Organ. Behav. 2018, 40, 126-146. [CrossRef]

28. Molden, D.C.; Lucas, G.M.; Rusbult, C.; Finkel, E.J.; Kumashiro, M. Perceived Support for Promotion-Focused and Prevention-Focused Goals. Psychol. Sci. 2009, 20, 787-793. [CrossRef]

29. Hanke, S.; Rohmann, E.; Förster, J. Regulatory focus and regulatory mode-Keys to narcissists' (lack of) life satisfaction? Pers. Individ. Differ. 2019, 138, 109-116. [CrossRef]

30. Gorman, C.A.; Meriac, J.P.; Overstreet, B.L.; Apodaca, S.; McIntyre, A.L.; Park, P.; Godbey, J.N. A meta-analysis of the regulatory focus nomological network: Work-related antecedents and consequences. J. Vocat. Behav. 2012, 80, 160-172. [CrossRef]

31. Brenninkmeijer, V.; Hekkert-Koning, M. To craft or not to craft. Career Dev. Int. 2015, 20, 147-162. [CrossRef]

32. Petrou, P.; Demerouti, E. Trait-level and week-level regulatory focus as a motivation to craft a job. Career Dev. Int. 2015, 20, 102-118. [CrossRef]

33. Hetland, J.; Hetland, H.; Bakker, A.B.; Demerouti, E. Daily transformational leadership and employee job crafting: The role of promotion focus. Eur. Manag. J. 2018, 36, 746-756. [CrossRef]

34. DiPietro, W.R.; Anoruo, E. Creativity, innovation, and export performance. J. Policy Model. 2006, 28, 133-139. [CrossRef]

35. De Stobbeleir, K.E.M.; Ashford, S.J.; Buyens, D. Self-Regulation of Creativity at Work: The Role of Feedback-Seeking Behavior in Creative Performance. Acad. Manag. J. 2011, 54, 811-831. [CrossRef]

36. Amabile, T.M.; Conti, R.; Coon, H.; Lazenby, J.; Herron, M. Assessing the work environment for creativity. Acad. Manag. J. 1996, 39, 1154-1184. [CrossRef]

37. Golden, J.H.; Shriner, M. Examining Relationships between Transformational Leadership and Employee Creative Performance: The Moderator Effects of Organizational Culture. J. Creat. Behav. 2017, 53, 363-376. [CrossRef]

38. Wu, C.-H.; Parker, S.K.; De Jong, J.P.J. Need for Cognition as an Antecedent of Individual Innovation Behavior. J. Manag. 2011, 40, 1511-1534. [CrossRef]

39. Adams, G.A.; King, L.A.; King, D.W. Relationships of job and family involvement, family social support, and work-family conflict with job and life satisfaction. J. Appl. Psychol. 1996, 81, 411-420. [CrossRef]

40. Allen, T.D.; French, K.A.; Dumani, S.; Shockley, K.M. A cross-national meta-analytic examination of predictors and outcomes associated with work-family conflict. J. Appl. Psychol. 2020, 105, 539-576. [CrossRef]

41. Amstad, F.; Meier, L.L.; Fasel, U.; Elfering, A.; Semmer, N.K. A meta-analysis of work-family conflict and various outcomes with a special emphasis on cross-domain versus matching-domain relations. J. Occup. Health Psychol. 2011, 16, 151-169. [CrossRef] [PubMed]

42. Lockwood, P.; Jordan, C.H.; Kunda, Z. Motivation by positive or negative role models: Regulatory focus determines who will best inspire us. J. Personal. Soc. Psychol. 2002, 83, 854-864. [CrossRef] 
43. Petrou, P.; Demerouti, E.; Peeters, M.C.W.; Schaufeli, W.B.; Hetland, J. Crafting a job on a daily basis: Contextual correlates and the link to work engagement. J. Organ. Behav. 2012, 33, 1120-1141. [CrossRef]

44. Van Wingerden, J.; Derks, D.; Bakker, A.B. The Impact of Personal Resources and Job Crafting Interventions on Work Engagement and Performance. Hum. Resour. Manag. 2015, 56, 51-67. [CrossRef]

45. Grandey, A.A.; Cropanzano, R. The Conservation of Resources Model Applied to Work-Family Conflict and Strain. J. Vocat. Behav. 1999, 54, 350-370. [CrossRef]

46. Brislin, R.W. Back-Translation for Cross-Cultural Research. J. Cross-Cult. Psychol. 1970, 1, 185-216. [CrossRef]

47. Netemeyer, R.G.; Boles, J.S.; McMurrian, R. Development and validation of work-family conflict and family-work conflict scales. J. Appl. Psychol. 1996, 81, 400-410. [CrossRef]

48. Lu, J.; Siu, O.; Spector, P.E.; Shi, K. Antecedents and outcomes of a fourfold taxonomy of work-family balance in Chinese employed parents. J. Occup. Health Psychol. 2009, 14, 182-192. [CrossRef]

49. Leana, C.R.; Appelbaum, E.; Shevchuk, I. Work Process and Quality of Care in Early Childhood Education: The Role of Job Crafting. Acad. Manag. J. 2009, 52, 1169-1192. [CrossRef]

50. Zhou, Q.; Hirst, G.; Shipton, H. Context matters: Combined influence of participation and intellectual stimulation on the promotion focus-employee creativity relationship. J. Organ. Behav. 2011, 33, 894-909. [CrossRef]

51. George, J.M.; Zhou, J. Understanding when bad moods foster creativity and good ones don't: The role of context and clarity of feelings. J. Appl. Psychol. 2002, 87, 687-697. [CrossRef] [PubMed]

52. Berdicchia, D.; Masino, G. The Ambivalent Effects of Participation on Performance and Job Stressors: The Role of Job Crafting and Autonomy. Hum. Perform. 2019, 32, 220-241. [CrossRef]

53. Vahedi, A.; Krug, I.; Westrupp, E. Crossover of parents' work-family conflict to family functioning and child mental health. J. Appl. Dev. Psychol. 2019, 62, 38-49. [CrossRef]

54. Liu, C.; Spector, P.E.; Shi, L. Cross-national job stress: A quantitative and qualitative study. J. Organ. Behav. 2007, 28, 209-239. [CrossRef]

55. Preacher, K.J.; Zhang, Z.; Zyphur, M.J. Multilevel structural equation models for assessing moderation within and across levels of analysis. Psychol. Methods 2016, 21, 189-205. [CrossRef]

56. Maia, A.D.H.N.; Luiz, A.J.B.; Campanhola, C. Statistical Inference on Associated Fertility Life Table Parameters Using Jackknife Technique: Computational Aspects. J. Econ. Entomol. 2000, 93, 511-518. [CrossRef]

57. Hollar, D.W. The Method of Path Coefficients. In Trajectory Analysis in Health Care; Springer: Cham, Germany, 2017; pp. 49-72.

58. Rogers, W.M.; Schmitt, N. Parameter Recovery and Model Fit Using Multidimensional Composites: A Comparison of Four Empirical Parceling Algorithms. Multivar. Behav. Res. 2004, 39, 379-412. [CrossRef]

59. Bandalos, D.L. The Effects of Item Parceling on Goodness-of-Fit and Parameter Estimate Bias in Structural Equation Modeling. Struct. Equ. Model. 2002, 9, 78-102. [CrossRef]

60. Yoo, W.-J.; Oh, I. Effect of Work-Family Balance Policy on Job Selection and Social Sustainability: The Case of South Korea. Sustainability 2017, 9, 849. [CrossRef]

61. Hill, E.J. Work-Family Facilitation and Conflict, Working Fathers and Mothers, Work-Family Stressors and Support. J. Fam. Issues 2005, 26, 793-819. [CrossRef]

62. Kossek, E.E.; Ozeki, C. Work-family conflict, policies, and the job-life satisfaction relationship: A review and directions for organizational behavior-human resources research. J. Appl. Psychol. 1998, 83, 139-149. [CrossRef]

63. Vieira, J.M.; Matias, M.; Lopez, F.G.; Matos, P.M. Work-family conflict and enrichment: An exploration of dyadic typologies of work-family balance. J. Vocat. Behav. 2018, 109, 152-165. [CrossRef]

64. Tims, M.; Bakker, A.B.; Derks, D. Daily job crafting and the self-efficacy - performance relationship. J. Manag. Psychol. 2014, 29, 490-507. [CrossRef]

65. Grant-Vallone, E.J.; Donaldson, S.I. Consequences of work-family conflict on employee well-being over time. Work Stress 2001, 15, 214-226. [CrossRef]

66. Ryan, R.M.; Deci, E.L.; Vansteenkiste, M. Autonomy and Autonomy Disturbances in Self-Development and Psychopathology: Research on Motivation, Attachment, and Clinical Process. Dev. Psychopathol. 2016, 1-54. [CrossRef]

67. Nielsen, K. Review Article: How can we make organizational interventions work? Employees and line managers as actively crafting interventions. Hum. Relat. 2013, 66, 1029-1050. [CrossRef] 
68. Rindfleisch, A.; Malter, A.J.; Ganesan, S.; Moorman, C. Cross-Sectional versus Longitudinal Survey Research: Concepts, Findings, and Guidelines. J. Mark. Res. 2008, 45, 261-279. [CrossRef]

69. Böckerman, P.; Ilmakunnas, P. The Job Satisfaction-Productivity Nexus: A Study Using Matched Survey and Register Data. ILR Rev. 2012, 65, 244-262. [CrossRef]

70. Grund, S.; Lüdtke, O.; Robitzsch, A. Multiple Imputation of Missing Data for Multilevel Models. Organ. Res. Methods 2017, 21, 111-149. [CrossRef]

71. Maertz, C.P.; Boyar, S.L.; Maloney, P.W.; Boya, S.L. A theory of work-family conflict episode processing. J. Vocat. Behav. 2019, 115, 103331. [CrossRef]

72. Xia, N.; Zhong, R.; Wang, X.; Tiong, R. Cross-domain negative effect of work-family conflict on project citizenship behavior: Study on Chinese project managers. Int. J. Proj. Manag. 2018, 36, 512-524. [CrossRef]

73. Lapierre, L.M.; Li, Y.; Kwan, H.K.; Greenhaus, J.H.; DiRenzo, M.S.; Shao, P. A meta-analysis of the antecedents of work-family enrichment. J. Organ. Behav. 2017, 39, 385-401. [CrossRef]

(C) 2020 by the authors. Licensee MDPI, Basel, Switzerland. This article is an open access article distributed under the terms and conditions of the Creative Commons Attribution (CC BY) license (http://creativecommons.org/licenses/by/4.0/). 